Forthcoming in slightly revised version in International Journal of Game Theory, 2007

\title{
A Simple "Market Value" Bargaining Model for Weighted Voting Games: \\ Characterization and Limit Theorems
}

\author{
Guillermo Owen \\ Department of Mathematics \\ Naval Post-Graduate School \\ Monterey, California \\ Ines Lindner \\ CORE \\ Catholic University of Louvain \\ 1384 Louvain-la-Neuve, Belgium \\ Scott L. Feld \\ Department of Sociology \\ Purdue University \\ Bernard Grofman \\ Department of Political Science, University of California, Irvine \\ Bgrofman@uci.edu \\ Leonard Ray \\ Department of Political Science \\ Louisiana State University
}




\begin{abstract}
Feld, Grofman and Ray (2003) offer a bargaining model for weighted voting games that is a close relative of the nucleolus and the kernel. They look for a set of weights that preserves winning coalitions that has the property of minimizing the difference between the weight of the smallest and the weight of the largest Minimum Winning Coalition. They claim that such a set of weights provides an a priori measure of a weighted voter's bribeworthiness or market value. Here, after reviewing the basic elements of their model, we provide a characterization result for this model and show its links to other bargaining model approaches in the literature. Then we offer some limit results showing that, with certain reasonable conditions on the distributions of weights, as the size of the voting body increases, the values of bribeworthiness we calculate will approach both the weights themselves and the Banzhaf scores for the weighted voting game. We also show that, even for relatively small groups using weighted voting, such as the membership of the European Council of Ministers (and its precedessors) 1958-2003, similarities among the usual a priori power scores, bribeworthiness/market value, and the weights themselves, will be quite strong.
\end{abstract}


Building on the work of Feld, Grofman and Ray (2003), the approach we offer is very similar in spirit to work from the game theoretic literature on bargaining games such as the Aumann-Maschler bargaining set, and to closely related work on "near-core" solutions such as the nucleolus and the kernel (Aumann and Maschler, 1964; Maschler, Peleg and Shapley, 1979; Schmeidler, 1969; see also McKelvey, Ordeshook and Winer, 1978; Sudhölter, 2001). But it is even more similar to the work of Young (1978) and that of Taylor and Zwicker (1997; see also Taylor and Zwicker, 1993) and other work on bribery models (e.g., Snyder, 1991), as well as to work on power rankings based on membership in minimal winning coalitions (e.g.; Morriss, 2002). ${ }^{1}$.

Specifically, we suggest that the set of values that minimizes the range of values (i.e. highest minus lowest) of the size of the minimum winning coalitions in a game will determine what we might call the approximate fungible power scores, or approximate market values. In contrast, the nucleolus can be thought of as minimizing the maximum complaints made by coalitions, while the kernel seeks to balance claims by individuals.

Maschler (1992) points out that the Aumann-Maschler bargaining model and related approaches (the kernel and the nucleolus) assume that a given coalition has been formed, and then ask how the members of that coalition will bargain over the spoils that coalition can gain. ${ }^{2}$ Here, however, rather than assuming bargaining among the members of an already formed coalition, we posit an external entrepreneur making bids to individuals with the aim of assembling a winning coalition, and seeking to minimize the total amount of bribes s/he pays out by paying potential members of some winning coalition no more than s/he is "worth" -- in a setting where the structure of the weighted game is such that one can usually replace that member with some one or more others to achieve a different coalition that will also have a majority sufficient for winning. ${ }^{3}$

The chief attractions of the bargaining model variant we offer are threefold. First, while it is a kissing cousin to other better known methods, it can be described and explained quite simply. Second, its roots are relatively intuitive. 
Third, and perhaps most importantly for present purposes, we have written a computer algorithm that will allow us to calculate its values.

\section{Market Values in Homogenous Majority Voting Games}

To motivate our bargaining model variant, we begin with what are called homogeneous weights, i.e., a weighted voting game in which all minimal winning coalitions (henceforth abbreviated MWCs) have equal total weights (Zwicker and Taylor, 1997: 51). Consider a e five-voter example, where A is given a weight of 3 , and the other four actors a weight of 1 , with a quota of four. This is a homogeneous game. The minimal winning coalitions (MWCs) are A, together with any one of B, C, D and E; or the set $\{\mathrm{B}, \mathrm{C}, \mathrm{D}, \mathrm{E}\}$. Of course there are an infinite number of possible weights (plus quotas) which give rise to the same MWCs. ${ }^{4}$ Nonetheless, if we are given a game which gives rise to some set of minimal winning coalitions, it seems reasonable to represent that game in the most parsimonious way possible, and if we can find homogeneous weights to represent a game it seems reasonable to do so. ${ }^{5}$ For games with homogeneous weights, weights can be regarded as measures of each actor's market value/bribeworthines. Moreover, even for such seemingly easy to model games, the market values so determined can be quite far from the values determined by indices such as those of Banzhaf or Shapley-Shubik.

We begin with an analysis of simple majority games. In such games, neglecting ties, winning coalitions and coalitions with power to block winning outcomes are one and the same. Our model assumes that the primary value of votes is their value in exchange. The question we examine is how much each voter's share of weights is worth to an outsider who would purchase a collective decision. For a majority rule game, purchasing a collective decision requires purchasing a majority vote. Since it is reasonable to assume that the purchaser will not pay any more than necessary, it seems reasonable that he will purchase no more than a minimal winning coalition. Furthermore, since purchasers are willing to pay the same amount for any minimal coalition, if actors are otherwise 
indifferent among alternatives, the value of all minimal winning coalitions should converge towards having the same total price.

For any weighted majority rule voting game, if we could set up a series of linear equations in which the sum of the values of the actors in each minimal winning coalition is equal to the sum of the values in every other minimal winning coalition, and we normalize those values to sum to one, and that set of simultaneous equations has a unique solution, then the values so arrived at would give us a natural way to establish the relative market values (bribeworthiness) of each actor. For homogenous games, we have a nice result. 
Proposition 1: If a weighted majority rule voting game is homogeneous and decisive, ${ }^{6}$ then this set of linear equations involving minimal winning coalitions ${ }^{7}$ has a solution in which the market value (bribeworthiness) of any nondummy actor is proportional to that actor's weight. ${ }^{8}$

For games with homogeneous weights we can thus arrive at a notion of what we shall call fungible power, i.e., a situation in which weight and power are the same.

We will illustrate this proposition with the previous example, where A has three votes and each of the other four voters has a single vote, and thus each minimal coalition has exactly four votes. Our approach focuses attention on the fact that the three votes of actor A are directly substitutable for the votes of any three other actors, and that should be reflected in their power scores -- $\underline{\text { at least if }}$ we neglect transaction costs. But, then, by symmetry, the actor whose share is three votes should have market power equal to the total of any other three voters. If values are normalized, then the market value scores are $(.430, .143, .143, .143$, $.143)$.

Note that these weights are substantially different from what we got from the two standard power scores: the Banzhaf values of $(.64, .09, .09, .09, .09)$, and the Shapley-Shubik power scores of $(.60, .10, .10, .10, .10)$. Unlike the usual power score approach we do not assume that an actor who is pivotal in many coalitions will be more heavily bribed. Rather, since only one coalition will actually form, we ask what, in that coalition, is a reasonable "bribe" for that actor, given that all actors in the winning coalition will have to be paid "what they are worth." Note also that the method we have initially used to assessing market value makes no assumptions whatsoever about the likelihoods of particular coalitions, or about the extent of common interests among actors. Indeed, in the calculations we gave, it turns out not to matter how many different coalitions an actor is decisive or pivotal in. Rather, what matters is her imputed market power relative to set of coalitions in which s/he might find herself. 
Unfortunately, there are sets of weights for which there is no functionally equivalent homogeneous set of weights. ${ }^{9}$ For example, consider a weighted voting game in which A, B, C, D, E, F have, respectively, weights $6,5,4,3,2,1$, totaling 21 , with a vote quota of 11 votes. It can be readily determined that these weights are not homogeneous. ACD is a minimal winning coalition with 13 votes, and $\mathrm{AB}$ is another MWC, but it has 11 votes. Since all MWCs do not have the same total votes, the set of weights is not homogeneous. With further analysis, it is also apparent that there does not exist any homogeneous set of weights that is functionally equivalent to these weights in terms of giving rise to the same set of minimal winning coalitions. To see this, we simply observe that if all minimal winning coalitions in the game above would have the same totals, then, i. a., the weight of ACE would have to equal that of $\mathrm{ADE}$, and therefore the weight of $\mathrm{C}$ would have to equal that of $\mathrm{D}$. On the other hand, $\mathrm{BCE}$ is a minimal winning coalition, but BDE is not-- so C and D can never have the same weights under this decision rule. This is sufficient to show that there can be no homogeneous set of weights for this game. We can generalize this intuition as follows.

Proposition 2: Market values are uniquely defined only for games that can be represented with homogeneous weights. ${ }^{10}$

We can illustrate this proposition using the weighted majority rule voting game example discussed immediately above. The minimum winning coalitions are $\{A, B\},\{A, C, D\},\{A, C, E\},\{A, C, F\},\{B, C, D\},(A, D, E\},\{B, D, E, F\}$. If we equate the values of the members of each of these minimal winning coalitions to one another, we get the set of equations below: $\mathrm{A}+\mathrm{B}=\mathrm{A}+\mathrm{C}+\mathrm{D}=\mathrm{A}+\mathrm{C}+\mathrm{E}=\mathrm{A}+\mathrm{C}+\mathrm{F}=\mathrm{B}+\mathrm{C}+\mathrm{D}=\mathrm{A}+\mathrm{D}+\mathrm{E}=\mathrm{B}+\mathrm{D}+\mathrm{E}+\mathrm{F}$.

Normalizing, we also require: $\mathrm{A}+\mathrm{B}+\mathrm{C}+\mathrm{D}+\mathrm{E}=1$. However, it is easy to see that there is no consistent solution to this set of equations. ${ }^{11}$

The fact that most voting games cannot be represented with homogeneous weights might seem to be a major limitation of our approach. But we will show how we can extend our notion of fungible power scores beyond the case of games with 
homogeneous weights for the case of games where a set of constraining equations does not have a solution, by considering the best approximation to homogeneous weights.

\section{Conceptualizing Bribeworthiness for Weighted Majority Rule Voting Games without Homogeneous Weights by Calculating Approximate Market Values}

We previously suggested that all minimal winning coalitions should have the same total value, because an outsider would not pay more for any one minimal winning coalition than for any other. But we would argue that, even if there is no way to make the values exactly equal, there will still be a tendency towards making the values of the minimal winning coalitions as similar as possible. Specifically, we suggest that the set of values that minimizes the range of values (i.e. highest minus lowest) will determine what we might call the approximate fungible power scores, or approximate market values. Determining precise bounds for the set of weights with minimal discrepancies is a complex linear programming problem, but we have been able to estimate these power scores by using an algorithm involving a simple least-squares minimization and successive approximations. ${ }^{12}$ This process seems to work well. Starting with an arbitrary set of weights, we can generally find a new set of weights that reduce the difference in weights of the largest and smallest minimum winning coalition; but better weights become more elusive as we seek to improve further.

Let us again consider the system of equations above, for a game with weights of $6,5,4,3,2$, and 1 , respectively, with a majority quota of 11 , now with the aim of generating a "plausible" set of weights.

$<<$ Table 1 about here $>>$

While both our approximate market values and the Banzhaf scores recognize the equivalence of the actors initially given weights of 2 and 3 , there are big differences in the relative weights of some of the other actors. Specifically, our value for the actor with smallest weights is more than twice her Banzhaf score, and our value for the actor with the fourth-highest weighting is much less than her Banzhaf score. As a consequence, the 
ratio between the fourth actor and the first is $2: 1$ for our approach, compared with 5:1 for the Banzhaf scores. ${ }^{13}$

\section{Plausible Mechanisms for Bribery}

We can imagine a number of different mechanisms by which bribery of the sort contemplated in this paper might be implemented, but two stand out for their intuitive plausibility. In each, the potential briber has in mind how much a favorable outcome is worth to him/her.

In one, the briber offers a total bribe to some particular minimal winning coalition, and expects the members of this coalition to bargain among themselves about how to share this bribe among themselves. In such a situation, actors might assess their marginal value to coalitions in terms of the likelihood that if a given coalition fails to form because they, a pivotal member of that coalition refuse to join it, they could still expect to be a member of some other winning coalition in which they would be pivotal. While this probability can be defined in urn model terms, even in this case, we might think that actors would consider not their probability of being in a coalition in which they are decisive (or pivotal) but rather their value to the coalitions in which they are, with equivalent (sets of) actors being paid the same bribe. This latter type of collective bargaining agreement story offers one type of rationale that has been offered for the nucleolus and related concepts (Maschler, 1992: 611). ${ }^{14}$

A second way to think of the coalition formation process makes use of ideas from the literature on sequential coalition formation. (See e.g., Brams, 1972, Brams and Garrigo-Pico, 1975; Brams and Riker, 1972; Grofman, 1982; Straffin and Grofman, 1984; Grofman, 1996; Grofman, Straffin and Noviello, 1996.) Here the bribe offerer can be thought of as fishing for bribe-takers, one or more at a time, and throwing them back in if they demand too large a bribe. This "fishing" continues until a winning coalition is reached. ${ }^{15}$

While both these mechanisms posit only a single briber, we believe the idea of market value can be extended to the two competing bribers case along the lines discussed in Owen (1992). ${ }^{16}$ 


\section{Robustness of Minimal Winning Coalitions}

Because our modeling approach is based on the idea of those with a stake in the outcome "bribing" voters to either achieve a particular outcome or to block change from the status quo, there might appear to be no reason for a briber to purchase more than a minimal winning coalition. Nonetheless, for two reasons, we might anticipate that observed voting coalitions would be larger than minimal winning.

First, some unbribed voters might vote for the winning outcome even if they get no bribe. Consequently, even though actors are only willing to pay for minimal winning coalitions, the "free" votes might make the actual winning coalitions considerably larger than minimal. Of course, if there are voters who can be counted on to vote as the briber wants without being bribed, and if the briber knows who they are, then the size of the coalition which must be bribed in order to assembly a minimal winning coalition is reduced, and we can simply do the market value calculations for the set of remaining voters. ${ }^{17}$

Second, however, some processes for forming minimal winning coalitions can actually result in larger than minimal outcomes. Consider, for example, what happens if we apply the sequential "fishing for minimal winning coalitions" process to the game with four voters, A, B, C and D, with weights 1, 2, 3 and 4 , respectively and a quota of 6. . If the briber's sequence of contacts is first A, then $\mathrm{C}$, than $\mathrm{D}$, and each accepts the bribes offered them, and no reneging on the part of either briber or bribee is possible, then the winning coalition formed will be of weight 8 , and will be non- minimal-winning, since member A can be deleted without affecting the winning status of the coalition. ${ }^{18}$

\section{Approximately Fungible Power in Qualified Majority Rule Non- Homogeneous Weighted Voting Games}

Note that our discussion above applies to majority rule, i.e., where either a coalition is winning or its complement is winning. These ideas can readily be extended to qualified majority rule (i.e. involving higher than majority quotas). A qualified majority rule is homogeneous when all minimal winning coalitions have the same values as one another and all minimal blocking coalitions have the 
same value as one another. Such sets of weights, if they exist, are unique up to a scalar multiplier, just as for majority rule. For homogeneous qualified majority rule weighted voting games it seems straightforward to use the weights as market values.

When a qualified majority rule game does not possess a representation in terms of homogeneous weights then, just as with majority rule games, there is a discrepancy between the largest and smallest MWC, but there is also a discrepancy between the smallest and largest minimum blocking coalition (MBC). We would now suggest that, for qualified majority rule games, approximately fungible power or approximate market share values be defined as the weights that minimize the larger of these two discrepancies. 


\section{Applications to the European Union}

We show in Table 2, for the period 1958-2003, the actual EU weights, the Banzhaf scores, and our computer algorithm-based estimates of the best-fitting market values, i.e., the weight assignments that bring the game closest to homogeneity.

$$
<<\text { Table } 2 \text { about here }>>
$$

Note that, as we eyeball the data, the estimated market share weights and the actual weights are close, and appear to be getting closer as the number of members of the Council of Ministers increases over the five weight assignments we are looking at. But of course, we must be careful in interpreting this finding since there are many different "actual" weights that could have been used to represent the same set of minimal winning coalitions. Indeed, in 1981 the resemblance between the actual weights and our estimated weights in Table 2 underestimates the degree of fit of the market value model, since that game is actually homogeneous -- a fact that we do not see from the actual weights, but can only discover when we look for weights that will bring us closer to homogeneity. 19 


\section{Propositions about Convergence Among Alternative Approaches to Power}

\section{Market-Based Power and Weights in the Limit}

Although, we can readily find hypothetical (or even actual) examples in which the best estimates of market share values give us minimal winning coalitions of substantially unequal weight, in practice, often the "optimal" weights/approximate market share values generated by our computer program will produce small differences between the weight share of the largest and the smallest MWC, even when the size of the weighted voting body is relatively small. In the previous section of the paper we presented empirical results for the EU Council of Ministers about the discrepancies between the largest and smallest MWCs and MBCs to provide unequivocal evidence that problems caused for our approximation approach to market values by the existence of non-homogeneous MWCs may not be that serious in at least some real world settings. We also suggested that the similarities tended to increase with an increase in the size of the Council of Ministers.

We can generalize that insight. For very large voting bodies, under plausible conditions, we might expect the differences between the weight share of the largest and the smallest MWC to be very small, indeed. Now we turn to results about limiting theorems. We will consider larger and larger sets of voters, with certain assumptions.

Suppose that the quota, $q$, is given, not as a fixed number of votes, but rather as some fraction (say .5 or .667) of the total number of votes. This $q$ is kept fixed. We then define an increasing chain, as a sequence of sets, $A_{1} \subset A_{2} \subset \ldots A_{k}$ $\subset A_{k+1} \subset \ldots$ of players. The total number of players grows without bound. Each of the players, $i$, is assigned a weight, $w_{i}$, a positive integer, which is the number of votes he has. (We disregard the existence of dummies.) Then, for a given $A_{k}$, a winning coalition will be any coalition that has at least $q a_{k}$ (or, in some case, more than $q a_{k}$ ) votes, where $a_{k}$ is the total number of votes in $A_{k}$. We then let $h_{k}$ be the smallest integer that has this property. Thus, the game in $\boldsymbol{A}_{\boldsymbol{k}}$ is simply a voting game in which any coalition with at least $h_{k}$ votes wins. 
Now, in any minimal winning coalition $\mathrm{S}$, the total number of votes is at most $h_{k}+w_{m}-1$, where $w_{m}$ is the weight of the weakest player in S. In turn, this $w_{m}$ $\leqslant w_{M, k}$, where $w_{M, k}$ is the weight of the strongest player in $A_{k}$. Note that equality might actually hold here. For example, in a game with a total of 73 votes, suppose $q=0.5$. Then any coalition with at least 37 votes will win. Suppose that, among the 73 votes, total, there are 10 players with 4 votes each (and none with more than 4). Then these 10 players form a minimal winning coalition, with a total of 40 votes. Thus the excess here is 3 votes, i.e., exactly $w_{M, k^{-1}}-1$.

We now put a condition on the weights of the several players:

Assumption 1: there is a maximal value, $\alpha$, such that no player in the chain has more than $\alpha$ votes.

With Condition 1, we see that the discrepancy can never be more than $\alpha-1$. In fact, any minimal winning coalition has at least $h_{k}$, and at most $h_{k}+\alpha-1$ votes. Similarly, any minimal blocking coalition will have at least $b_{k}=a_{k}-h_{k}+1$ votes, and (by an argument similar to the one above) at most $b_{k}+\alpha-1$ votes. Moreover, note that this upper bound can only be attained if there are sufficiently many voters with this maximal weight - enough to form a winning coalition all by themselves. An easy corollary of this is that the relative discrepancy (i.e., the discrepancy as a fraction of total votes) will be bounded by $(\alpha-1) / a_{k}$. Thus, in the limit, the relative discrepancy goes to zero.

The next question is whether the weights can be changed in some way to decrease the absolute discrepancy. This can always be done by dividing all weights by the same constant, so we will assume that all weights are integers, and that the greatest common divisor of these weights is 1 .

It is clear that, in many cases, the discrepancy can be decreased. For example, suppose that, in some $A_{k}$, there are 50 voters with weight 2 , and one (call him $j$ ) with weight 3 . This means $a_{k}=103$, so that, with $q=0.5$, the winning coalitions are those with at least 52 votes. However, there are minimal winning coalitions consisting of voter $j$, along with 25 of the remaining voters. These have 53 votes, and thus there is a 
discrepancy of 1 unit. It is then possible to decrease the discrepancy by decreasing $j$ 's weight to 2 . Then all minimal winning coalitions have a total of 52 votes, and there is 0 discrepancy. The point is that player $j$ 's extra vote does him no good in this situation, and he is no more bribe-worthy than any of the other players.

In general, we can conceive of a situation in which some minimal winning coalitions have exactly $h$ votes, while one minimal winning coalition, $S$, has $h+d$ votes, where $d>0$. Thus there is a discrepancy of $d$ votes. Let $j \in S$, and suppose $j$ has $w_{j}$ votes, where $w_{j} \geqslant 2$. In that case, by decreasing $w_{j}$ to $w_{j}{ }^{\prime}=w_{j}-1$, the total number of votes in $S$ decreases to $h+d-1$. This would decrease the discrepancy unless $j$ belongs to some other winning coalition, $T$, with exactly $h$ votes. Then the total number of votes in $T$ would also decrease by 1 unit, so the discrepancy would still be equal to $d$. Therefore, we would like the following to happen: that every player belong to some winning coalition with exactly $h_{k}$ votes.

This same condition is important from another point of view. In fact, we would like $w_{j}$ to represent the bribeworthiness of player $j$. The briber wishes to "buy" a winning coalition as cheaply as possible. Thus we can expect that he will bribe, not merely a minimal winning coalition, but one for which the sum of the bribes is a minimum. Assume next that the players' demands are proportional to their weights. Now, if player $j$ does not belong to such a minimum-cost winning coalition, then she will never be bribed, i.e., the demand $w_{j}$ will have priced her out of the market. Once again, therefore, stability of the situation requires that each player belong to such a minimum-cost coalition.

To be sure of this, we make another assumption:

Assumption 2. Among the weights, there is some subset $W=\left\{w_{1}, w_{2}, \ldots, w_{r}\right\}$, with greatest common divisor equal to 1 . Moreover, for each $l, 1 \leq l \leq r$, the number of players (in set $A_{k}$ ) with weight $w_{l}$ grows without bound as $k \rightarrow \infty$.

With this assumption, we have the following:

Proposition 3. Under assumptions 1 and 2, then for sufficiently large $k$, each player $i \in A_{k}$ belongs to at least one coalition $T \subset A_{k}$ with exactly $h_{k}$ votes. 
Thus the discrepancy cannot be decreased by the simple expediency of decreasing j's weight.

Proof: the proof of this statement is given in the Appendix (see Lemma).

Of course, such a result holds also for blocking coalitions:

Corollary to Proposition 3. Under assumptions 1 and 2, then for sufficiently large $k$, each player $i \in A_{k}$ belongs to at least one coalition $T \subset A_{k}$ with exactly $b_{k}$ votes, where $b_{k}=a_{k}-h_{k}+1$.

\section{Market-Based Power and Banzhaf (or Shapley-Shubik) Values in the Limit}

The central claimed justification for making use of power scores is that the weights themselves are not good indicators of a voter's bargaining power. Yet, when we define voter bargaining power in "bribeworthiness" terms, the arguments above suggest that, for homogeneous games, power will actually be directly proportional to voter weight, and even for small non-homogenous games, power will often be approximately proportional to weight. Now we wish to show that, for large non-homogeneous games with many players, if the weight distribution satisfies certain assumptions, power will converge to be proportional to the voter weight.

Proposition 4. Under the same assumptions as in Proposition 1, and assuming that $q=0.5$, the Banzhaf-Coleman index will, in the limit as $k \rightarrow \infty$, be proportional to the number of votes.

Proof: this is given in Lindner and Machover (2003).

Note: Interestingly enough, proposition 4 above does not seem to generalize to the case where $q \neq 0.5$. See Chang, Chua and Machover (2004) who use simulation to test these results.

For the Shapley value, we will use one further definition. Given the chain $A_{1} \subset A_{2}$ $\subset \ldots A_{k} \subset A_{k+1} \subset \ldots$, we will say a weight $w$ is frequent if there exists $\beta>0$ such that, for all sufficiently large $k$, the number of voters with weight $w$ in set $A_{k}$ is at least $\beta a_{k}$. 
Proposition 5. Given the chain $A_{1} \subset A_{2} \subset \ldots A_{k} \subset A_{k+1} \subset \ldots$, suppose the weight $w_{i}$ is a frequent weight. Then in the limit, the product $a_{k} \varphi_{i} \rightarrow w_{i}$ as $k \rightarrow \infty$, where $\varphi_{i}$ is the Shapley value of a player with weight $w_{i}$.

Proof: see Lindner (2004) for this.

\section{Discussion}

While propositions 3-5 hold only in the limit, the empirical results we gave in the previous section for the European Council of Ministers suggest, that even for the relatively limited number of actors in the various historical Common Market and EU weighted voting games, there is considerable concordance of actual weights and power scores - at least once we specify the appropriate equivalent set of weights in each case that minimizes the discrepancy between largest and smallest minimum winning coalition. In this context we would also note that recent work of Gelman, Katz and Bafumi (2004: 662) finds that weights in the U.S. Electoral College majority rule weighted voting game in 2004 are very close to the a priori Shapley-Shubik values for that game, while Owen (1975) found a similar result for the 1970 Electoral College. 


\section{APPENDIX}

\section{Lemma:}

Let $A_{1} \subset A_{2} \subset \ldots A_{k} \subset A_{k+1} \subset \ldots$ be an increasing chain of sets of voters, with each voter $i$ having an integer number $w_{i} \geq 1$ of votes (his weight). Let $a_{k}$ be the total number of votes in set $A_{k}$, and for a given real number $q, 0<q<1$, let $h_{k}$ be the smallest integer $\geq$ $q a_{k}$. For any coalition $B$, let $w(B)$ be the total number of votes in $B$. Let $\alpha$ be an upper bound on all $w_{i}$, on all sets $A_{k}$. Assume that there are integers $z_{1}, z_{2}, \ldots, z_{r}$ such that (a) for each $j, 1 \leq j \leq r$, the number of voters with weight $z_{j}$ in set $A_{k}$ grows without bound as $k$ $\rightarrow \infty$, and (b) the greatest common divisor (g.c.d.) of $z_{1}, z_{2}, \ldots, z_{r}$ is 1 . Then, for sufficiently large $k$, each voter $i$ belongs to at least one coalition $T \subset A_{k}$ with $w(T)=h_{k}$.

\section{Proof:}

Since the $z_{j}$ have g.c.d. equal to 1 , we know any integer $m$ can be expressed in the form of a linear combination $x_{1} z_{1}+\ldots+x_{r} z_{r}$, where the $x_{j}$ are integers. More importantly, there exists a number, $s$, such that any $m \geq s$ can be expressed in the form $x_{1} z_{1}+\ldots+x_{r} z_{r}$, where the $x_{j}$ are non-negative integers. Clearly, if all are non-negative, then none can be larger than $m$ itself. From this it will follow that any integer $m$, with $s \leq m \leq s+\alpha$, can be written in the form $x_{1} z_{1}+\ldots+x_{r} z_{r}$, where the $x_{j}$ are non-negative integers, not greater than $s+\alpha$.

Choose now $k$ large enough so that

(a) $A_{k}$ contains a subset $S$ with at least $s+\alpha$ voters of each weight $z_{j}(1 \leq j \leq r)$.

(b) $A_{k}-S$ has at least one voter of each type.

(c) $w(S) \leq a_{k}-h_{k}$, and

(d) $s+2 \alpha \leq h_{k}$.

From the above discussion, we know that $S$ will have subsets $S^{\prime}$ such that $w\left(S^{\prime}\right)$ can have any integer value between $s$ and $s+\alpha$.

From (c) we have that

$$
w\left(A_{k}-S\right) \geq h_{k}
$$


From (d) we see that, for any player $i$,

$$
h_{k}-s-\alpha-w_{i} \geq 0
$$

There is no loss of generality, now, in assuming that $i \in A_{k}-S$. (In fact, by (b), even if $i \in S$, there will be some other player with the same weight in $A_{k}-S$.) Let $V=A_{k}-S-\{i\}$. We see then that $w(V) \geq h_{k}-w_{i}$. Since no voter has more than $\alpha$ votes, it will follow that, if we remove players, one by one, from the set, the total votes in the set can never decrease by more than $\alpha$ at each step. Thus we see that, for every $n$ satisfying $0 \leq n \leq h_{k}-$ $w_{i}-\alpha$, the set $V$ has a subset $T^{\prime}$ such that $n \leq w\left(T^{\prime}\right) \leq n+\alpha$. In particular, there is some $T^{\prime} \subset$ $V$ with

$$
h_{k}-s-w_{i}-\alpha \leq w\left(T^{\prime}\right) \leq h_{k}-s-w_{i}
$$

This means however that

$$
s \leq h_{k}-w_{i}-w\left(T^{\prime}\right) \leq s+\alpha .
$$

Thus, $S$ has at least one subset, $S^{\prime}$, with $w\left(S^{\prime}\right)=h_{k}-w_{i}-w\left(T^{\prime}\right)$. Now, let $T=$ $T^{\prime} \cup S^{\prime} \cup\{i\}$.

Since $T^{\prime}$ and $S^{\prime}$ are disjoint, and neither contains $i$, it follows that

$$
w(T)=w\left(T^{\prime}\right)+w\left(S^{\prime}\right)+w_{i}=h_{k}
$$

Q.E.D.

Note: the proof of the corollary is similar to this. We omit details. 
Table 1

Normalized Weights, Estimated Market Values, and Banzhaf Scores for an Illustrative Six Voter Majority Rule Weighted Voting Game

\begin{tabular}{|l|l|l|l|l|l|l|l|}
\hline Weights & 1 & 2 & 3 & 4 & 5 & 6 & $\begin{array}{l}\text { size } \\
\text { range of } \\
\text { MWCs }\end{array}$ \\
\hline $\begin{array}{l}\text { normalized } \\
\text { weights }\end{array}$ & .048 & .095 & .143 & .190 & .238 & .286 & .095 \\
\hline $\begin{array}{l}\text { Estimated } \\
\text { market } \\
\text { shares }\end{array}$ & .074 & .111 & .111 & .148 & .259 & .296 & .037 \\
\hline $\begin{array}{l}\text { Banzhaf } \\
\text { scores }\end{array}$ & .036 & .107 & .107 & .179 & .250 & .321 & \\
\hline
\end{tabular}




\section{Table 2}

Values of (normalized) EU Weights, Estimated Market-Values, and Banzhaf Scores: 1958-1995

(a) 1958

$\begin{array}{lllll}\begin{array}{l}\mathbf{1 9 5 8} \\ \text { wts }\end{array} & \begin{array}{l}\text { normalized } \\ \text { wts }\end{array} & \begin{array}{l}\text { normalized } \\ \text { wts2* }^{*}\end{array} & \begin{array}{l}\text { market value } \\ \text { wts2* }\end{array} & \begin{array}{l}\text { Banzhaf } \\ \text { scores }\end{array} \\ 1 & .059 & 0 & 0 & 0 \\ 2 & .118 & .125 & .141 & .143 \\ 2 & .118 & .125 & .141 & .143 \\ 4 & .235 & .250 & .240 & .238 \\ 4 & .235 & .250 & .240 & .238 \\ 4 & .235 & .250 & .240 & .238 \\ & & & & \end{array}$

(b) 1973

$\begin{array}{llll}\begin{array}{l}1973 \\ \text { wts }\end{array} & \begin{array}{l}\text { normalized } \\ \text { wts }\end{array} & \begin{array}{l}\text { market value } \\ \text { wts }\end{array} & \begin{array}{l}\text { Banzhaf } \\ \text { scores }\end{array} \\ 2 & .034 & .049 & .016 \\ 3 & .052 & .066 & .066 \\ 3 & .052 & .066 & .066 \\ 5 & .086 & .082 & .091 \\ 5 & .086 & .082 & .091 \\ 10 & .172 & .164 & .167 \\ 10 & .172 & .164 & .167 \\ 10 & .172 & .164 & .167 \\ 10 & .172 & .164 & .167\end{array}$


Table 2 (cont.)

Values of (normalized) EU Weights, Estimated Market-Values, and Banzhaf Scores: 1958-1995

\section{(c) 1981}

$\begin{array}{llll}\begin{array}{l}1981 \\ \text { wts }\end{array} & \begin{array}{l}\text { normalized } \\ \text { wts }\end{array} & \begin{array}{l}\text { market value } \\ \text { wts }\end{array} & \begin{array}{l}\text { Banzhaf } \\ \text { scores }\end{array} \\ 2 & .032 & .04 & .041 \\ 3 & .048 & .04 & .041 \\ 3 & .048 & .04 & .041 \\ 5 & .079 & .08 & .082 \\ 5 & .079 & .08 & .082 \\ 5 & .079 & .08 & .082 \\ 10 & .159 & .16 & .158 \\ 10 & .159 & .16 & .158 \\ 10 & .159 & .16 & .158 \\ 10 & .159 & .16 & .158\end{array}$

(d) 1986

$\begin{array}{llll}\begin{array}{l}1986 \\ \text { wts }\end{array} & \begin{array}{l}\text { normalized } \\ \text { wts }\end{array} & \begin{array}{l}\text { market value } \\ \text { wts }\end{array} & \begin{array}{l}\text { Banzhaf } \\ \text { scores }\end{array} \\ 2 & .026 & .026 & .029 \\ 3 & .039 & .048 & .046 \\ 3 & .039 & .048 & .046 \\ 5 & .066 & .067 & .067 \\ 5 & .066 & .067 & .067 \\ 5 & .066 & .067 & .067 \\ 5 & .066 & .067 & .067 \\ 8 & .105 & .107 & .109 \\ 10 & .132 & .126 & .129 \\ 10 & .132 & .126 & .129 \\ 10 & .132 & .126 & .129 \\ 10 & .132 & .126 & .129\end{array}$


Table 2 (cont.)

Values of (normalized) EU Weights, Estimated Market-Values, and Banzhaf Scores: 1958-1995

(e) 1995

$\begin{array}{llll}\begin{array}{l}\text { 1995 } \\ \text { wts }\end{array} & \begin{array}{l}\text { normalized } \\ \text { wts }\end{array} & \begin{array}{l}\text { market value } \\ \text { wts }\end{array} & \begin{array}{l}\text { Banzhaf } \\ \text { scores }\end{array} \\ 2 & .023 & .025 & .023 \\ 3 & .034 & .036 & .036 \\ 3 & .034 & .036 & .036 \\ 3 & .034 & .036 & .036 \\ 4 & .046 & .046 & .048 \\ 4 & .046 & .046 & .048 \\ 5 & .057 & .057 & .059 \\ 5 & .057 & .057 & .059 \\ 5 & .057 & .057 & .059 \\ 5 & .057 & .057 & .059 \\ 8 & .092 & .093 & .092 \\ 10 & .115 & .114 & .112 \\ 10 & .115 & .114 & .112 \\ 10 & .115 & .114 & .112 \\ 10 & .115 & .114 & .112\end{array}$





\section{REFERENCES}

Aumann, Robert and Michael Maschler. 1964. "The Bargaining set for Cooperative Games. " In M. L. Dresher, L. Shapley, and A. W. Tucker (eds.) Advances in Game Theory. Princeton, NJ: Princeton University Press, 443-476.

Axelrod, Robert M. 1970. Conflict of Interest: A Theory of Divergent Goals with Applications to Politics. Chicago: Markham Publishing Company.

Banks, Jeffrey S. 2000. Buying Supermajorities in Finite Legislatures." American Political Science Review 94 (3): 677-682.

Banzhaf, John F. 1965. “Weighted Voting Doesn't Work: A Mathematical Analysis.” Rutgers Law Review, 19: 317-343.

Bell, Roderick, David V. Edwards and R. Harrison Wagner. 1969. Political Power: A Reader in Theory and Research. New York: The Free Press.

Berg. Sven. 1999. "On Voting Power Indices and a Class of Probability Distributions, with Applications to EU Data." Group Decision and Negotiation 8: 17-31.

Bossert, Walter, Steven J. Brams and D. Marc Kilgour. 2002. "Cooperative and NonCooperative Truels: Little Agreement, but Does that Matter? Games and Economic Behavior 40: 185-202.

Brams, Steven J. 1968. "Measuring the Concentration of Power in Political Systems." American Political Science Review 62: 461-475.

Brams, Steven J. 1972. "A Cost-Benefit Analysis of Coalition Formation in Voting Bodies." In Richard G. Niemi and Hebert F. Weisberg (eds.) Probability Models of Collective DecisionMaking. Columbus, Ohio. Charles E. Merrill, 101-124.

Brams, Steven J. 1975. Game Theory and Politics. New York: Free Press.

Brams, Steven J. and Jose E. Garrigo-Pico. 1975. "Bandwagons in Coalition Formation: The 2/3rds Rule." American Behavioral Scientist 18 (March/April): 472-496.

Brams, Steven J. and William Riker 1972. "A Cost-Benefit Analysis of Coalition Formation in Voting Bodies." In James F. Herndon and Joseph L. Bernd (eds.) Mathematical Applications in Political Science, Volume 1. Charlottesville, Virginia: University Press of Virginia, 79-124.

Brink, R. van den. 2001. "An Axiomatization of the Shapley Value Using a Fairness Property." International Journal of Game Theory 30: 309-319. 
Carreras, Francesc and Guillermo Owen. 1988. "Evaluation of the Catalonian Parliament, 1980-1984." Mathematical Social Sciences 15(1): 87-92.

Champlin, John Rittenhouse. 1971. Power. New York: Atherton Press.

Chang, Pao-Li, Vincent C. H. Chua and Moshe Machover. 2004. "L. S. Penrose's Limit Theorem: Test by Simulation." Draft, London School of Economics

Coleman, James S. 1971. "Control of Collectivities and the Power of a Collectivity to Act." In B Lieberman (ed.) Social Choice. New York: Gordon and Breach, 277-287.

Dal Bo, Ernesto. "Bribing Voters.” Unpublished manuscript. Department of Economics, University of California, Berkeley.

Deegan, John. Jr. and Edward W. Packel. 1976. "To the (Minimal Winning) Victors Go the (Equally Divided) Spoils: A New Power Index for Simple N-Person Games.” Modules in Applied Mathematics, Mathematical Association of America.

Dubey, P. and Lloyd S. Shapley. 1979. "The Mathematical Properties of the Banzhaf Index." Mathematics of Operations Research, 4: 99-131.

Feld, Scott L. and Bernard Grofman. 1990. "A Theorem Connecting Shapley-Owen Power Scores and the Radius of the Yolk in Two Dimensions." Social Choice and Welfare, 7:71-74.

Feld, Scott L., Bernard Grofman and Leonard Ray. 2003. "The market value of weighted votes: An alternative approach to voting power." Paper presented at the Public Choice Society Annual Meeting, March 21-23, 2003, Nashville, TN. (Earlier versions were presented at the London School of Economics Workshop on Voting Power Analysis, August 9-11, 2002, and at the Japanese-American Conference on Mathematical Sociology, Vancouver, May 24, 2002.)

Felsenthal, Dan S. and Moshe Machover. 1995 "Postulates and Paradoxes of Relative Voting Power: A Critical Reappraisal.” Theory and Decision 38: 195-229.

Felsenthal, Dan S. and Moshe Machover. 1997. “The Weighted Voting Rule in the EU's Council of Ministers, 1958-1995, Intentions and Outcomes." Electoral Studies 16: 33-47.

Felsenthal, Dan S. and Moshe Machover. 1998. The Measurement of Voting Power: Theory and Practice, Problems and Paradoxes. Cheltenham, England: Edward Elgar.

Felsenthal, Dan S. and Moshe Machover. 2001a. "Myths and Meanings of Voting Power: Comments on a Symposium." Journal of Theoretical Politics 13 (1): 81-97.

Felsenthal, Dan S. and Moshe Machover. 2001b. "The Treaty of Nice and Qualified Majority Voting" Social Choice and Welfare 19 (3): 465-483. 
Fishburn, Peter C. and Steven J. Brams. 1996. "Minimal Winning Coalitions in WeightedMajority Voting Games." Social Choice and Welfare 13: 397-417.

Garrett, Geoffrey and George Tsebelis. 1999. "Why Resist the Temptation to Apply Power Indices to the European Union?" Journal of Theoretical Politics 11 (3): 291-308.

Gelman, Andrew, Jonathan Katz and Joseph Bafumi. 2004. "Standard Voting Power Indexes Do Not Work: An Empirical Analysis.” British Journal of Political Science. 34: 657-674.

Gillies, R. P., Guillermo Owen and R. van den Brink. 1992. "Games with Permission Structures: The Conjunctive Approach.” International Journal of Game Theory 20: 277-293.

Glazer, Amihai, Deborah Glazer, and Bernard N. Grofman. 1984. "Cumulative voting in corporate elections: Introducing strategy into the equations." South Carolina Law Review, 35(2):295-309.

Good I. J. and L. S. Mayer. 1975. "Estimating the Efficacy of a Vote." Behavioral Science 20(1): 2533.

Grofman, Bernard. 1981. "Fair Apportionment and the Banzhaf Index." American Mathematical Monthly, 88(1):1-5.

Grofman, Bernard N. 1982. "A dynamic model of protocoalition formation in ideological n-space." Behavioral Science, 27:77-90.

Grofman, Bernard. 1996. "Extending a dynamic model of protocoalition formation". In Norman Schofield (Ed.), Collective Decision Making: Social Choice and Political Economy. Boston: Kluwer-Nijhoff, 265-280.

Grofman, Bernard, Phillip Straffin and Nicholas Noviello. 1996. "The sequential dynamics of cabinet formation, stochastic error, and a test of competing models." In Schofield, Norman (Ed.) Collective Decision Making: Choice and Political Economy. Boston: Kluwer-Nijhoff, 281-293.

Grofman, Bernard and Guillermo Owen. 1982. "A Game Theoretic Approach to Measuring Degree of Centrality in Social Networks." Social Networks, 4:213-224.

Grofman, Bernard, Guillermo Owen, Nicholas Noviello and Amihai Glazer. 1987. "Stability and centrality of legislative choice in the spatial context." American Political Science Review, 81(2):539-553.

Groseclose, Tim. 1996. "An Examination of the Market for Favors and Votes in Congress." Economic Inquiry 34 (April): 320-340.

Groseclose, Tim and James M. Snyder Jr. 1996. "Buying Supermajorities.” American Political Science Review 90: 303-315. 
Groseclose, Tim and James M. Snyder Jr. 2000. "Vote Buying, Supermajorities, and Flooded Coalitions." American Political Science Review 94: 683- 684.

Gurk, H. M. and J. R. Isbell. 1959. "Simple Solutions.” In A. W. Tucker and R. D. Luce (eds.) Contributions to the Theory of Games, Volume 4. Princeton, NJ: Princeton University Press, pp. 247-265.

Holler Manfed J. (ed.) 1982. Power, Voting and Voting Power. Wurzburg, Germany: Physica Verlag.

Holler, Manfred J. and Guillermo Owen (eds.) 2001. Power Indices and Coalition Formation. Boston: Kluwer Academic Publishers.

Holler, Manfred and Mika Widgren. 1999. "Why Power Indices for Assessing EU DecisionMaking? Journal of Theoretical Politics 11: 321-330.

Hosli, M. 1993. "The Admission of the European Free Trade Association States to the European Community: Effects of Voting Power in the European Community Council of Ministers." International Organization 47: 629-643.

Hosli, M. 1995. "The Balance Between Small and Large: Effects of a Double-Majority System on Voting Power in the European Union." International Studies Quarterly 39: 351-370.

Hosli, M. 1996. "Coalitions and Power: Effects of Qualified Majority System in the Council of the European Union." Journal of Common Market Studies 34(2):255-273.

Konig, Thomas and Thomas Brauninger. "Decisiveness and Inclusiveness: Two Aspects of the Intergovernmental Choice of European Voting Rules." In Manfred Holler and Guillermo Owen (eds.) Power Indices and Coalition Formation. Boston: Kluwer Academic Publishers.

Lars, Jan-Erik and Sven Berg. 1999. "Relevance of Voting Power.” Journal of Theoretical Politics 11(3):309-319.

Laurelle, Annick and Mika Widgrén. 1998. "Is the Allocation of Voting Power Among EU States Fair?” Public Choice 94: 317-339.

Leech, Dennis. 1988. "The Relationship Between Shareholding Concentration and Shareholder Voting Power in British Companies: A Study of the Application of Power Indices for Simple Games." Management Science 34 (4): 509-527.

Leech, Dennis. 1990. "Power Indices and Probabilistic Voting Assumptions.” Public Choice 66: 293-299.

Leech, Dennis. 2002a. "An Empirical Comparison of the Performance of Classical Power Indices.” Political Studies 50(1):1-22. 
Leech, Dennis. 2002b. "Voting Power and the Governance of the International Monetary Fund. Annals of Operations Research 109(1-4): 375-397.

Leech, Dennis. 2002c. "Designing the Voting System for the Council of the European Union." Public Choice 113(3-4): 437-464.

Lindner, Ines. 2004. "Power Measures in Large Weighted Voting Games." Unpublished Ph.D. Dissertation, University of Hamburg.

Lindner, Ines and Moshe Machover. 2004. "L. S. Penrose's Limit Theorem: Proof of Some Special Cases." Mathematical Social Sciences, 47(1):37-49.

Luce, R. Duncan and Howard Raiffa. 1957. Games and Decisions. New York: Wiley.

Maschler, Michael. 1992. "The Bargaining Set, Kernel and Nucleolus." In Robert J. Aumann and Sergiu Hart (eds.) Handbook of Game Theory With Economic Applications, Vol. I.

Amsterdam: Elsevier Publishers, 591-667.

Maschler, Michael, B. Peleg and Lloyd S. Shapley. 1979. "Geometric Properties of the Kernel, Nucleolus and Related Solution Concepts." Mathematics of Operations Research 4: 303-333.

McKelvey, Richard, Peter Ordeshook and Mark Winer. 1978. "The Competitive Solution for NPerson Games Without Transferable Utility, with an Application to Committee Games." American Political Science Review 1978: 599-615.

Morriss, Peter. 2002. Power: A Philosophical Analysis, $2^{\text {nd }}$ ed. New York: Palgrave.

Napel, Stefan and Mika Widgrén, 2000. “Inferior Players In Simple Games.” Working Paper \#734, Research Institute of the Finnish Economy, Helsinki, Finland.

Nurmi, Hannu. 1982. "The Problem of the Right Distribution of Voting Power." In Manfed J. Holler (ed.) Power, Voting and Voting Power. Wurzburg, Germany: Physica Verlag.

Nurmi, Hannu and T. Meskanen. 1999. "A Priori Power Measures and the Institutions of the European Union.” European Journal of Political Research 35 (2): 161-179.

Owen, Guillermo. 1975. "Evaluation of a Presidential Election Game." American Political Science Review 69: 947-953.

Owen, Guillermo. 1982. "Modification of the Banzhaf-Coleman Index for Games with A Priori Unions." in Manfed J. Holler (ed.) Power, Voting and Voting Power. Wurzburg, Germany: Physica-Verlag,

Owen, Guillermo. 1986. "Values of Graph-Restricted games." SIAM Journal of Algebraic Discrete Methods 7: 210-220. 
Owen, Guillermo. 1995a. Game Theory, $3^{\text {rd }}$ Edition. San Diego, Academic Press.

Owen, Guillermo. 1992. "The Finagle Point for Characteristic Function games." In Reinhart Selten (ed.). Rational Interaction., Berlin: Springer Verlag, 35-43.

Owen, Guillermo. 1995b. "The Not Quite Non-Atomic Game: Homogeneous Games on Two Measures." International Journal of Game Theory. Vol. 24 :399-413.

Owen, Guillermo and Lloyd. S. Shapley. 1989. "Optimal Location of Candidates in Ideological Space." International Journal of Game Theory 18:125-142 and 339-356.

Pajala, Antti. 2004. "Voting Power and Constitutional Design - An Empirical Approach and Exercise." Presented at the Annual Meeting of the Public Choice Society, Baltimore, MD, March.

Penrose, L. S. 1946. “The Elementary Statistics of Majority Voting.” Journal of the Royal Statistical Society 109: 53-57.

Radzik, Tadeusz and Theo Driessen. 2001. "An Axiomatic Approach to Probabilistic Efficient Values for Cooperative Games.” In Manfred Holler and Guillermo Owen (eds.). Power Indices and Coalition Formation. Boston: Kluwer Academic Publishers.

Raunio, Tapio and Mattti Wiberg. 1998. "Winners and Losers in the Council: Voting Power Consequences of EU Enlargements.” Journal of Common Market Studies 36 (4): 549-562.

Riker, William. 1983. "A Reconciliation of Ball v. James and Reynolds v. Sims." Supreme Court Economic Review: 1980 Term 1, 39-68.

Saari, Donald and Katri Sieberg. 2001. "Some Surprising Properties of Power Indices." Games and Economic Behavior 36(2):241-263.

Schmeidler, D. 1969. "The Nucleolus of a Characteristic Function Game.” SIAM Journal of Applied Mathematics 17: 1163-1170.

Shapley, Lloyd S. and Martin Shubik. 1954. "A Method for Evaluating the Distribution of Power in a Committee System." American Political Science Review 48: 787-792.

Snyder, James. 1991. “On Buying Legislatures.” Economics and Politics 3: 93-109.

Straffin, Philip D. Straffin, Jr. 1977. “Homogeneity, Independence and Power Indices.” Public Choice 30: 107-118.

Straffin, Philip D. Straffin, Jr. and Bernard Grofman. 1984. "Parliamentary Coalitions: A Tour of Models." Mathematics Magazine 57(5): 259-274. 
Sudhölter, Peter. 2001. "Equal Treatment for Both Sides of Assignment Games in the Modified Least Core." In Manfred Holler and Guillermo Owen (eds.) Power Indices and Coalition Formation. Boston: Kluwer Academic Publishers.

Sutter, Matthias. 2000a. "Fair Allocation and Re-Weighting of Votes and Voting Power in the EU Before and After the Next Enlargement." Journal of Theoretical Politics 12(4): 433-449.

Sutter, Matthias. 2000b. "Flexible Integration, EMU, and Relative Voting Power in the EU." Public Choice 104: 41-62.

Taylor, Alan and William Zwicker. 1993. "Weighted Voting, Multicameral Representation and Power." Games and Economic Behavior 5: 170-181.

Taylor, Alan and William Zwicker. 1997. "Interval Measures of Power." Mathematical Social Sciences 33(1):23-74.

Tsebelis, George and Geoffrey Garrett. 1997. "Why Power Indices Cannot Explain DecisionMaking in the European Union." In D. Schmidtchen and Robert Cooter (eds.) Constitutional Law and the Economics of the European Union. Cheltenham, UK: Edward Elgar.

Tsebelis, George and Geoffrey Garrett. 2000. "Legislative Procedure in the European Union." European Union Politics 1: 9-36.

Tsebelis, George, Chris Jensen, Anastassios Kalandrakis and Amie Kreppel. 2001. "Legislative Procedure in the European Union: An Empirical Analysis." British Journal of Political Science 31: 573-599.

Widgren, Mika. 1994. "Voting Power in the EU and the Consequences of Two Different Enlargements." European Economic Review 38: 1153-1170.

Widgren, Mika. 2001. "On the Probabilistic Relationship Between the Public Good Index and the Normalized Banzhaf Index." In Manfred Holler and Guillermo Owen (eds.) 2001. Power Indices and Coalition Formation. Boston: Kluwer Academic Publishers, 127-142.

Young, H. Peyton. 1978. "Power, Prices and Incomes in Voting Systems." Mathematical Programming 14: 129-148.

Zwiebel, Jeffrey. "Block Investment and Partial Benefits of Corporate Control." Review of Economic Studies, 62 (April): 161-185. 
${ }^{1}$ For example, Morriss (2002:167-68), following Goldman (1974) proposes a rank-ordered idea of power by ranking players by the number of minimal winning coalitions of which they are a part ( breaking ties by looking at membership in coalitions of the next smallest size).

${ }^{2}$ See also Maschler, Peleg and Shapley (1979).

${ }^{3}$ Our approach is thus analogous to identifying a market clearing price structure.

4 For example, if we assigned weights of one 9 and four $4 \mathrm{~s}$, or weights of one 15 and four $4 \mathrm{~s}$, we get the same MWCs as previously. These weighted voting games all allow the "big guy" and one "little guy: or all four little guys to make a decision. Yet, these relative weights are very different from one and different from our original representation. But more importantly for present purposes, these two later representations do not have the property that all minimal winning coalitions have the same total value. With one 9 and four $4 \mathrm{~s}$, the mixed coalition adds up to 13 , while the little guy coalition adds to 16 . With one 15 and four $4 \mathrm{~s}$, the mixed coalition adds to 19 , and the little guy coalition adds to 16 . So, these weights do not meet our condition.

${ }^{5}$ Moreover, for a game with homogeneous weights, if we either assume no dummies or that all dummies have a weight of zero, then a game with weights that are exact multiples of those weights also gives rise to the same set of MWCs, i.e., the weighted voted game with A given a weight of $3 \mathrm{k}$ and with four actors with weights of $1 \mathrm{k}$, with a quota of $4 \mathrm{k}$, will generate the same set of MWCs as the homogeneous game with weights of $(3,1,1,1,1)$ with a quota of 4 .

${ }^{6} \mathrm{~A}$ game is decisive if the complement of any losing coalition is winning.

${ }^{7}$ If we focus on minimal winning coalitions we are implicitly excluding dummies, who would be assigned a value of zero.

${ }^{8}$ This result follows from results in Gurk and Isbell (1959). The solution to this set of equations gives us, i.a., the nucleolus of the game.

${ }^{9}$ Elsewhere we have generated some theorems about conditions sufficient to guarantee the existence of a set of homogeneous weights. These results are available upon request from the authors. .

${ }^{10}$ This result follows from results in Gurk and Isbell (1959).

${ }^{11}$ Even if we have homogeneous weights, this does not guarantee that the solution to the relevant system of equations will be unique when the game is not decisive. Consider the homogeneous four voter game with weights 1, 2, 2 and 3 and a quota of 5 votes. To assign consistent weights so that each minimum winning coalition gets the same payoff we must have $\mathrm{B}=\mathrm{C}$ and $\mathrm{D}=\mathrm{A}+\mathrm{B}$. One possibility is $(1 / 8,1 / 4$, $1 / 4,3 / 8)$, but another is $(0,1 / 3,1 / 3.1 / 3)$. And, there are an infinite number of other feasible weight assignments. We are indebted to Guillermo Owen (personal communication, 2004) for calling this example to our attention. In this example, the second solution given is the nucleolus (see Maschler, 1992). 
12 The computer program we use to calculate optimal weights automatically excludes dummies. While our estimates of optimal weights are not the same with and without dummies, given our ideas about the bribing process as resulting in zero values for dummies, we believe the calculations with the dummies excluded are the correct ones.

${ }^{13}$ If the Banzhaf scores shown in Table 1 were themselves to used as weights, they would describe a slightly different game from the original game; i.e. they do not yield the same set of MWCs. In the original game, $\{5,3,2,1\}$ is a MWC, but the Banzhaf scores for these actors add to exactly .50 , not enough for the quota. A slight modification of these scores (increasing the value for the 1 and decreasing it for the 4) reproduces the original game. When that modification is made, the range in values of the MWCs is more than .10 for these values, which is greater than for the original normalized weights.

${ }^{14}$ If bribery is to be of a given coalition, we might think of this as analogous to purchasing an entire meal from a prix fixe menu with an already specified set of items that can be purchased as a package, and with some items found in more than one package.

${ }^{15}$ We may think of this piscatorial perspective as treating bribery more like choice from an a la carte menu than from a pre-specified package of entries.

16 There one bidder chooses (the incumbent) chooses an imputation $\mathbf{x}$, while another (the challenger) chooses a second imputation $\mathbf{y}$ which presumably dominates $\mathbf{x}$. Now the imcumbent looked for a $\mathbf{z}$ as close as possible to $\mathbf{x}$ that would dominate $\mathbf{y}$. For simple games of the sort considered here, this calculation was not that difficult, but for more general games it was incredibly difficult.

${ }^{17}$ We can thus neglect "fixed votes" since they do not affect the fundamental structure of our results.

${ }^{18}$ We might think, though, for transaction costs reduction reasons, if no other, that potential bribers would begin by trying to bribe the more highly weighted actors.

19 The question of sensitivity to alternative weight assignments is a potentially important issue. Elsewhere some of the present authors have developed some propositions about the maximum adjustments to the elements of a given set of weights that are possible without changing the nature of the MWCs and MBCs in the new game. We show that, for certain not unreasonable assumptions about the weights, we can expect that, as the number of actors increases, the calculations we get about the differences between minimum and maximum minimal winning and minimal blocking coalitions will be insensitive to which of the possible weight assignments we use, since the maximum feasible differences should shrink toward zero. 